\title{
Puquitinib Mesylate
}

National Cancer Institute

\section{Source}

National Cancer Institute. Puquitinib Mesylate. NCI Thesaurus. Code C162556.

The mesylate salt of puquitinib, an orally available selective inhibitor of the delta form of phosphatidylinositol 3-kinase (PI3-kinase subunit delta; PI3K-delta; PI3Kdelta), with potential antineoplastic activity. Upon oral administration, puquitinib selectively binds to the ATP-binding pocket of PI3K-delta and prevents the activation of the PI3K/AKT signaling pathway. This decreases proliferation of and induces cell death in PI3K-delta over-expressing tumor cells. PI3K-delta also plays a key role in the B-cell receptor (BCR) signaling pathway and the proliferation of certain hematologic cancer cells. The targeted inhibition of PI3K-delta is designed to preserve PI3K signaling in normal, non-neoplastic cells, thereby minimizing serious side effects. 